\title{
DRY MATTER ESTIMATION OF STANDING CORN WITH NEAR-INFRARED REFLECTANCE SPECTROSCOPY
}

\author{
Matthew F. Digman ${ }^{1, *}$, Jerry H. Cherney ${ }^{2}$, Debbie J. Cherney ${ }^{3}$ \\ ${ }^{1}$ Biological Systems Engineering, University of Wisconsin, Madison, Wisconsin, USA. \\ 2 Section of Soil and Crop Sciences, School of Integrative Plant Science, Cornell University, Ithaca, New York, USA. \\ ${ }^{3}$ Animal Science, Cornell University, Ithaca, New York, USA. \\ * Correspondence:digman@wisc.edu.
}

\section{HIGHLIGHTS}

- Quadratic relationships were established to relate ear moisture or stover moisture to whole plant moisture, and they explained $90 \%$ and $84 \%$ of whole plant moisture, respectively.

- Based on our observations, the moisture content of a corn field can be estimated within $\pm 1 \%$ w.b. in 19 out of 20 fields by sampling 5-10 plants.

- The calibration offered by $\mathrm{SCiO}$ was successful at predicting oven-dried moisture content based on traditional NIRS metrics of $\mathrm{R}^{2}=0.92, \mathrm{RMSE}=3.6, \mathrm{RPD}=3.2$, and $\mathrm{RER}=15$. However, the $95 \%$ prediction bands were $\pm 6.9 \% \mathrm{w} . \mathrm{b}$. which would indicate little utility in estimating ear moisture content.

- Based on a prediction model that was developed using the data collected for this study, a significant instrument-toinstrument bias was observed, indicating the necessity of including multiple SCiO devices in calibration spectra collection.

\begin{abstract}
Determining the appropriate time to harvest whole-plant corn is an essential factor driving the successful preservation via anaerobic fermentation (ensiling). The current options for timely on-farm monitoring of corn moisture in the field include selecting a set of representative plants, chopping and drying a subsample, or harvesting a portion of the field using a harvester equipped with an on-board moisture sensing system. Both methods are time-consuming and expensive, limiting their practicality for harvest decision-making.

This work's objective was to develop a practical solution that utilizes the moisture content of the ear to estimate wholeplant moisture. An improvement of this method was also considered that utilized a hand-held near-infrared reflectance spectroscopy (NIRS) device to predict ear moisture in situ. Based on the data collected during this work, a quadratic relationship was developed where ear moisture explained $90 \%$ of the variability in whole-plant corn moisture. However, based on our observations, the hand-held NIRS evaluated would have little utility in predicting whole-plant corn moisture with either the calibration developed here or provided by the manufacturer. The manufacturer's prediction model yielded the best result with an $R^{2}$ of 0.92 , and a ratio of performance to deviation of 3.19 . However, the 95\% prediction band was $\pm 6.85 \%$ w.b. Finally, we determined that for a corn field uniform in appearance, sampling five to ten plants is likely to provide a reasonable estimate of field moisture.
\end{abstract}

Keywords. Corn silage, Forage analysis, Harvest timing, Moisture content, NIRS.

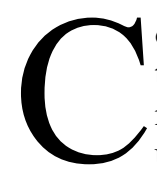
orn must be ensiled at the proper moisture for optimum fermentation, yet determining whole-plant moisture is problematic. Many studies have evaluated the effect of corn harvest timing on yield, quality, and ensiling (Darby and Lauer, 2002; Lewis et al., 2004; Cox and Cherney, 2005). Harvesting corn too wet will

\footnotetext{
c) (1) (5) $\odot$ The authors have paid for open access for this article. This c. ${ }_{\mathrm{BY}} \mathrm{NC}_{\mathrm{NO}}$ work is licensed under a Creative Commons AttributionNonCommercial-NoDerivatives 4.0 International License https://creative commons.org/licenses/by-nc-nd/4.0/.

Submitted for review on 27 January 2021 as manuscript number ITSC 14506; approved for publication as a Research Article by the Information Technology, Sensors, \& Control Systems Community of ASABE on 23 August 2021.
}

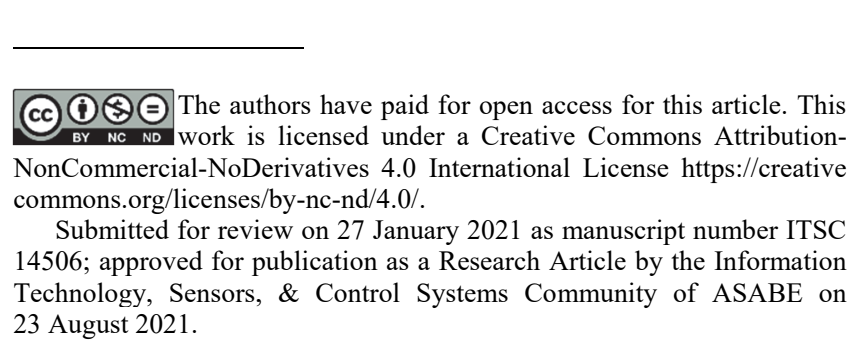

reduce yield potential and result in poor fermentation, seepage, and reduced animal intake, while harvesting too dry also can reduce yield potential by poor packing and fermentation, and result in molding and reduced digestibility.

The current options for timely on-farm monitoring of corn moisture in the field include selecting a set of representative plants and chopping and drying a subsample or chopping a short swath in the field using a harvester equipped with on-board or handheld NIR equipment (Digman and Shinners, 2008; Long et al., 2016; Donnelly et al., 2018). Each method is limited by obtaining a chopped, whole-plant sample.

There are more options for estimating grain moisture than whole-plant moisture of corn. Thus, one objective of this 
research is to investigate the relationship between wholeplant and grain moisture. These instruments include benchtop NIRS and instruments designed to measure the dielectric constant of a bulk sample of grain.

The most accurate and precise portable instruments utilize the Unified Grain Moisture Algorithm (UGMA; Funk, 2001). The UGMA defines a parallel-plate transmission cell geometry at a frequency range, density correction and calibration parameters (Funk and Gillay, 2020). However, a survey of commercially-available instruments reveals the upper limit of prediction to be about $45 \%$ (Dickey-john GAC/ miniGAC 2500UGMA, Perten AM 5200-A, Auburn, Ill.). This limit is just below the useful moisture prediction range for monitoring corn dry-down for whole-plant harvest and anaerobic storage (ensiling). Thus, there is a need to evaluate instrumentation to predict ears at a high-moisture content.

There have been many advancements in the field of nearinfrared reflectance (NIR) spectroscopy instrumentation and calibration development. The technique is routinely used to analyze forage samples for producers. Specifically, new advanced manufacturing techniques have allowed the development of miniaturized spectrometers that can be used on farms and are less sensitive to temperature, dust, or vibrations (Yan, 2018; Bec et al., 2020). Portable spectrometers are now installed on various field equipment and have numerous hand-held options (Crocombe, 2018), with many potential uses yet to be evaluated.

Recently, a commercially available NIRS instrument (SCiO, Consumer Physics, Tel-Aviv, Israel) has been calibrated to meet this need. The instrument purports to predict corn kernel moisture from $8 \%$ to $80 \%$ with a calibration developed over 1000 corn samples (SCiO, 2021). However, the calibration is proprietary and to the authors' knowledge, no independent validation has been published. Additionally, to be useful in predicting when to harvest whole-plant corn a relationship between ear and whole-plant moisture needs to be established.

The overall goal of this work is to develop a rapid tool to assess whole-plant corn dry down to ensure proper ensiling and minimal production of environmentally damaging effluent. The specific objectives of the work presented here were (1) to characterize changes in ear and stover moisture

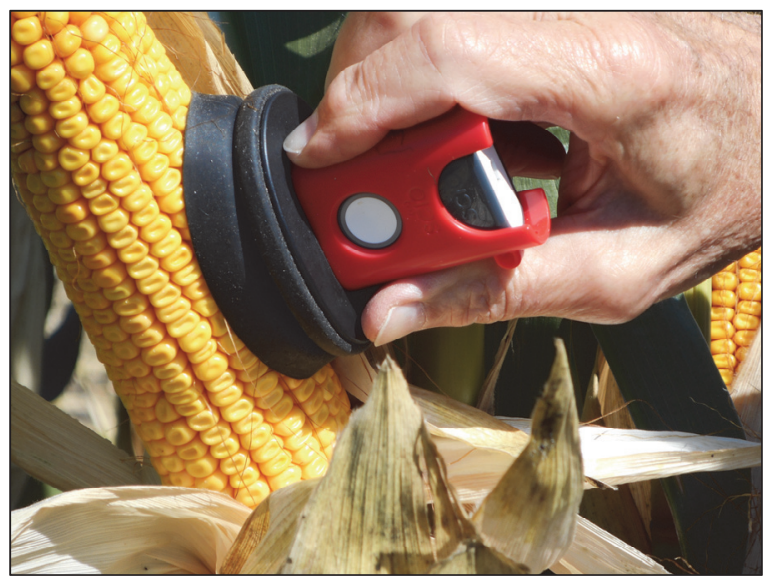

content in corn, (2) to determine how many corn plants are needed to represent the moisture variation within a field, (3) to evaluate a commercially available hand-held NIRS and calibration to predict ear moisture, (4) to develop an open model for the commercial instrument to understand the capabilities of the hardware, and (5) to understand the utility of the calibration between devices.

\section{Materials AND Methods}

\section{SCANNING PRocedures}

The SCiO (Consumer Physics, Tel-Aviv, Israel) instrument has a post dispersive optical filter matrix technology with a spectral range of 740 to $1070 \mathrm{~nm}$ (U.S. Patent $9,448,114$, Goldring et al., n.d.). The collection window is $7 \times 9 \mathrm{~mm}$, but the actual scan area is difficult to estimate, as the light source is adjacent to the collection window, with a $1 \mathrm{~cm}$ spacing between the window and sample surface. The available software from Consumer Physics included a calibration for whole ear corn moisture which we evaluate in this study in addition to developing our own calibration.

Before using the $\mathrm{SCiO}$ each day, the internal calibration program was run with the lens covered. The instrument was inserted into a plastic holder with an outer flexible rubber cowling made specifically for corn ears by Consumer Physics, maintaining approximately a $1 \mathrm{~cm}$ distance between the sample surface and the sensor window and excluding external light from the sensor (fig. 1).

\section{CORN FIELd SAMPLING}

In the fall of 2019, 23 corn fields in central, western, and northern New York state were randomly sampled, with 15 to 50 plants per field cut at a $20 \mathrm{~cm}$ stubble height and scanned using the $\mathrm{SCiO}$. The husk was removed from the ear, and ears were scanned five times from the top to bottom of each ear. Leaf-sheath was removed from the internode directly below the ear attachment, and the internode surface also was scanned five times in different locations. Fields were sampled beginning 5 September to 11 October 2019, with a total of 840 plants sampled. In addition, ears from 739 of these plants were scanned five times each, with scans processed by a Consumer Physics calibration application to predict grain moisture.

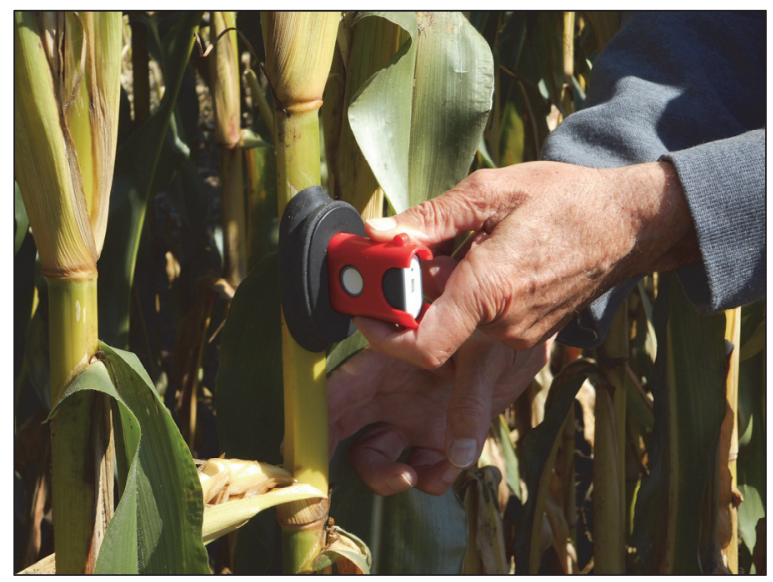

Figure 1. Attachment to SCiO NIR instrument to maintain a precise distance between the scan window and corn ear (left) and stalk (right) surface and to exclude external light. 
Sampling of outside corn rows was avoided, as outside row plants often have two developed ears depending on the hybrid, due to reduced competition and increased light penetration. After NIR scanning, plants were processed as follows. Corn ears were removed from the stalk and kept intact and dried at $60^{\circ} \mathrm{C}$ in a forced-air oven for at least five days until a constant weight was obtained. Corn stover (excluding grain and cob) was chopped using a Hege 44 stationary plot chopper (Wintersteiger Inc., Salt Lake City, Utah) mounted on a truck bed and dried at $60^{\circ} \mathrm{C}$ for two days.

\section{CALIBRATION AND VALIDATION}

Calibrations were developed by relating near-infrared spectra to oven moisture reference values. Spectra were exported from the $\mathrm{SCiO} \mathrm{Lab}$ web application and subsequently imported into Wolfram Mathematica (Version 12.1, Wolfram Research, Inc., Champaign, Ill.). Mathematica was used for all subsequent data analysis, including averaging, conversion from reflectance to absorbance, mean centering, math pre-treatment, partial least square regression (PLS), cross-validation, and computation of model performance statistics.

Partial least square regression (PLS) was used to explore the relationship between response (moisture content of ears or stalk) and predictor variables (spectra). The number of latent variables (LVs) was selected by plotting the variance explained by each LV for both the cross-validation and calibration training sets. The optimal number of LVs was selected at the first local minimum, given the standard error of calibration (SEC) was not divergent from the standard error of cross-validation (SECV).

In all of the calibration models, spectra from the five repeated scans were averaged and converted to absorbance $(\log (1 / R))$. Both spectra and reference values were mean-centered. Additional spectral preprocessing techniques explored included none, standard normal variate and detrend, SavitzkyGolay smoothing, first derivative, and second derivative. The impact of pretreatment on the number of latent variables, SEC, SECV, coefficient of determination $\left(\mathrm{R}^{2}\right)$, and the ratio of performance to deviation (RPD) was considered before selecting the optimal spectral transformation. NIRS repeatability was determined as the standard error between the predictions of the reference value given repeated measurements of the same ear or stalk. Ultimately the performance of the model was assessed using the validation set from a field location that was independent of the calibration data.

The success of the prediction models was assessed based on the coefficient of determination $\left(\mathrm{R}^{2}\right)$, root mean square error of prediction (RMSEP), residual prediction deviation (RPD) (Ward et al., 2011; Foster et al., 2013). RMSEP = $\operatorname{sqrt}\left(\left(\operatorname{sum}(\mathrm{R} 1-\mathrm{P} 1)^{2}\right) / \mathrm{n}\right)$, where $\mathrm{R} 1=$ reference data set, $\mathrm{P} 1=$ predicted data set, and $n=$ number of samples. $\mathrm{RPD}=$ reference data set standard deviation (SD) / RMSEP.

\section{RESUlTS AND DISCUSSION}

\section{Moisture Trends in CORn Plants}

Oven DM determinations for corn silage are reasonably precise for use as an absolute gold standard or reference value; duplicate oven DM determinations recently obtained by subsampling corn silage (Cherney et al., 2021) had a standard error of the laboratory (SEL) of $0.348(n=208)$. In our current study, the entire corn plant was dried, avoiding any sampling or subsampling errors. Two years of fall corn plant sampling produced relatively consistent relationships among ear, stover, and whole plant moisture before, during, and after the corn silage harvest season (fig. 2). In general, stover moisture remained at a high value for an extended period early in the season, while ear moisture declined rapidly during the same period.

Initially, ear moisture was similar to stover moisture, but the difference between them increased sharply until well past the optimum whole plant moisture $(\sim 68 \%)$ for initiating silage harvest (fig. 3). The quadratic regression suggests that moisture content is equal for stover and ear at about $82 \%$ and that eventually, they will be equal again when the wholeplant dry down is complete. At about 57\% whole-plant moisture, the stover begins to lose moisture faster than ear.

Variability in corn due to plant-to-plant variation (Cherney et al., 1996) has been removed in figure 3 by using field means. The remaining variation is likely environmental variation as well as variation due to corn hybrid genetics such as brown-midrib (BMR) and stay-green traits. Ten of the fields contained BMR hybrids, indicated in red in figure 3. Stay-green effects are difficult to assess, as one of the types of stay-green is simply a cosmetic version, with little effect on plant moisture (Thomas and Smart, 1993). Some types of stay-green corn plants do retain stover moisture longer compared to typical plants (Ettle and Schwarz, 2003; Arriola et al., 2012), but the data in figure 4 indicate that most of the current corn hybrids begin ear dry down well before stover

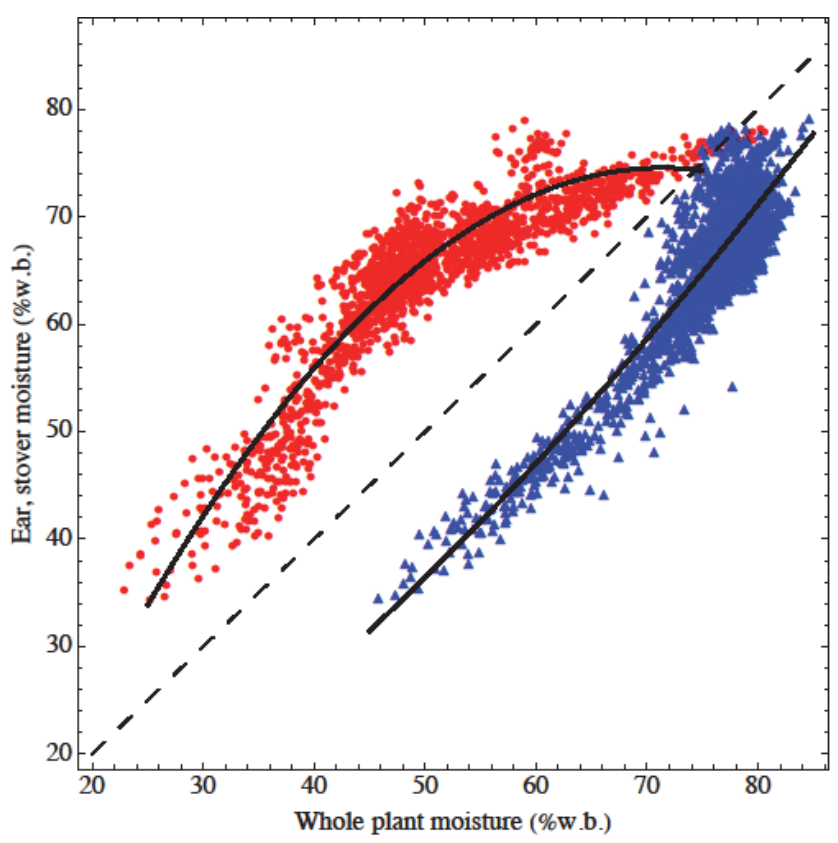

Figure 2. Ear, stover, and whole plant moisture relationships for individual corn plants collected from 56 fields in New York in the fall of 2019 and 2020 . Observations of stover moisture content vs. whole plant moisture are represented by red dots and the quadratic model $-0.018 \mathrm{x}^{2}$ $+2.87 \times-33.4, R^{2}=0.90$. Blue triangles represent ear moisture content vs. whole plant moisture. The data is also represented by the fitted model $0.028 x^{2}-2.24 x+78.3, R^{2}=0.89$. 


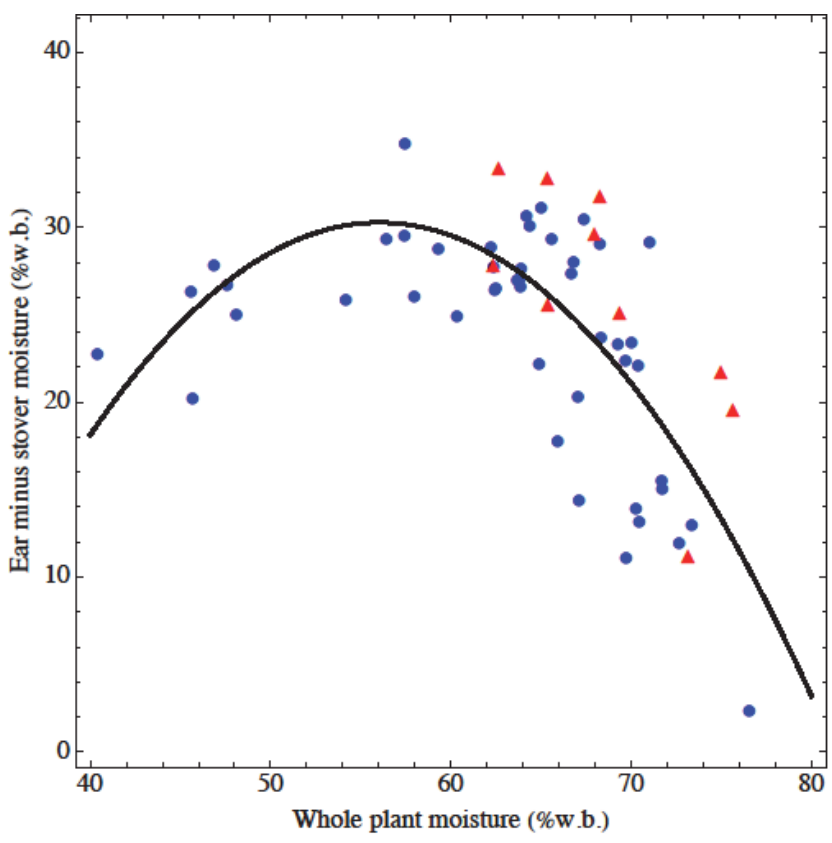

Figure 3. Difference between stover and ear moisture as the corn plant matures. Means of 15 to 50 individual corn plants per field collected from 56 fields in New York in the fall of 2019 and 2020. The 10 red triangles are brown-midrib (BMR) fields.

dry down. The minimal dry down of stover up to harvest time will make it difficult to estimate whole plant moisture for harvest timing using stover moisture estimations.

\section{Plant-to-Plant Moisture Variation}

In 10 of the fields, we sampled between 40 and 50 plants per field. If we assume that the mean of 40 to 50 plants is an adequate representation of the field's moisture content, we can estimate how many plants are required to collect a

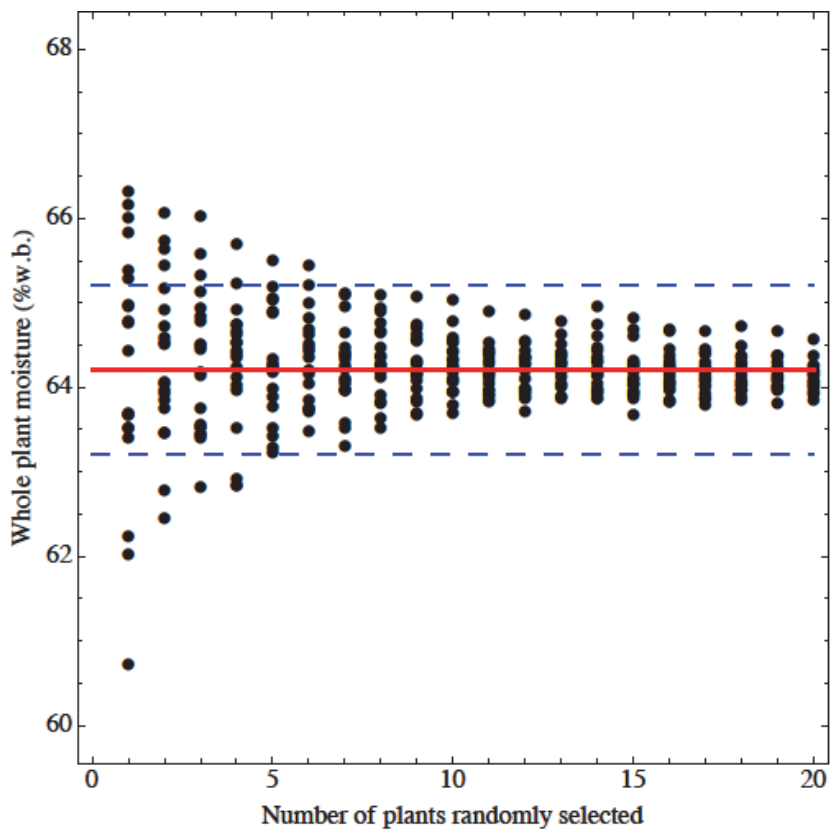

Figure 4. Twenty cycles of randomly selecting from 1 to 20 plants from a set of 50 plants taken from a corn field on 9-20-19 in central New York. The 50-plant mean was $64 \%$ (red line), with a range of $60 \%$ to $67 \%$ (blue dashed lines). representative sample for moisture determination. An example field with 20 cycles of randomly selecting from 1 to 20 plants for a moisture estimate is shown in figure 5 . If the goal is to collect a sample that is within $\pm 1 \%$ unit of moisture 19 out of 20 times, this requires from 3 to 16 plants per field for the 10 fields. The average number of plants required was 6.6 $(\mathrm{SD}=4.17)$. One field was much more variable than the others, with a $13 \%$ unit moisture range among 50 plants sampled, possibly due to uneven germination. Ten plants were sufficient for 9 of 10 fields, while for 6 of 10 fields, 5 plants were sufficient. For a corn field uniform in appearance, sampling 5 to 10 plants is likely to provide a reasonable estimate of field moisture.

\section{SCiO Consumer Physics Corn Grain Calibration}

For 2019 samples only, 739 ears from corn plants (husk removed) were scanned with the $\mathrm{SCiO}$ and scans were processed using a Consumer Physics corn grain calibration application (fig. 5). The wide range in ear moisture resulted in a very high $\mathrm{R}^{2}$, and very little bias was observed. According to validation performance criteria suggested by Malley et al. (2005) and Ward et al. (2011), the $\mathrm{R}^{2}$ of 0.92 , RMSEP of 3.6 and RPD of 3.19 indicated a moderately successful prediction of ear moisture. However, the RPD was very near the border between moderately successful and successful. The coefficient of determination $\left(\mathrm{R}^{2}\right)$ is very strongly influenced by the range of the reference data, such that a high $\mathrm{R}^{2}$ for a wide data range is not necessarily indicative of a useful calibration. Although these criteria imply relative success, the large $95 \%$ prediction band ( $\pm 6.85 \%$ w.b.) indicated that results using this application would be of limited value for a corn grain producer.

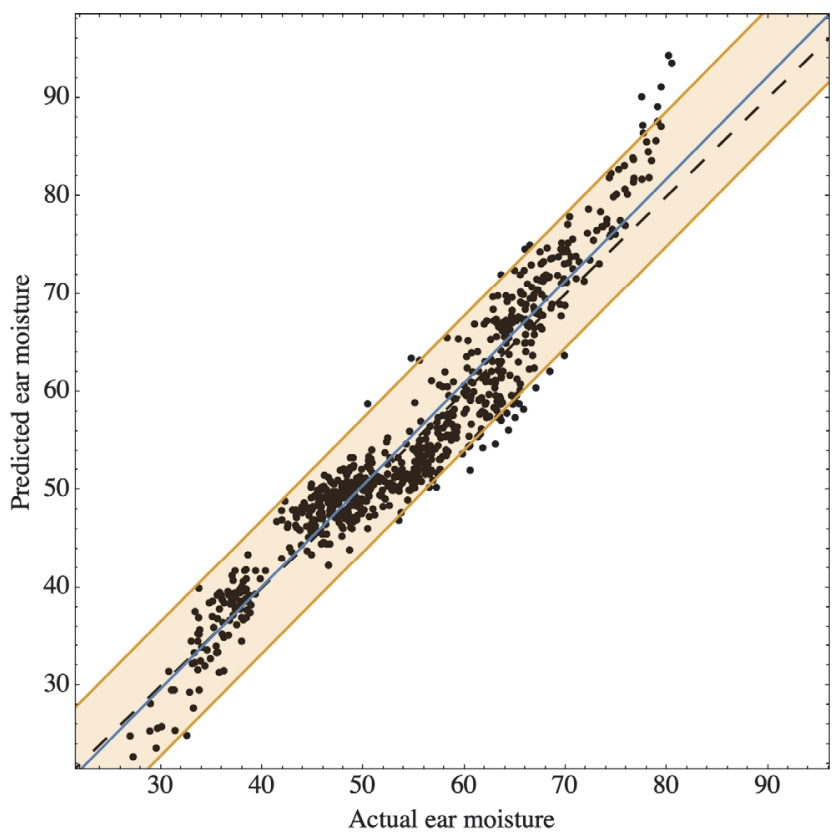

Figure 5. Relationship between laboratory ear moisture (determined by oven DM procedure) and SCiO ear moisture using a Consumer Physics calibration. Blue regression line dashed black 1:1 relationship and shaded $95 \%$ confidence bands based on single observations. 


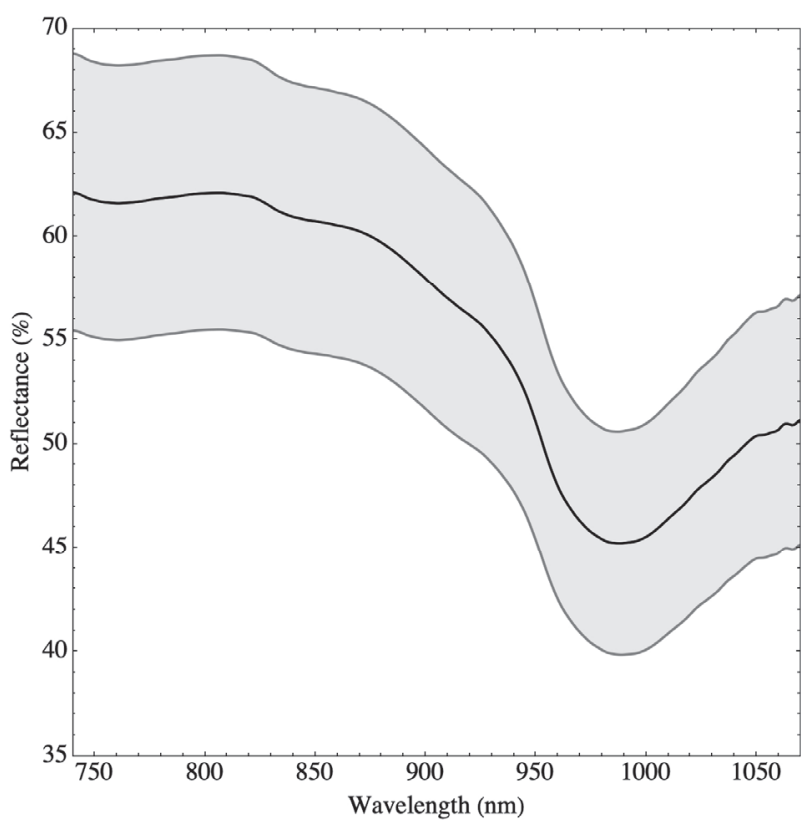

Figure 6. Mean and \pm 1 standard deviation of spectra collected from ears (left) and corn stalks using the SCiO device and scanning accessory.

\section{CALIBRATION AND VALIDATION RESUlts FOR SAMPLES OBSERVED IN THIS STUDY}

Spectra were exported from the $\mathrm{SCiO} \mathrm{Lab}$ web tool (fig. 6). The relative reflectance values for the corn ear were higher than the stover but a distinct peak in each occurred at 980 and $990 \mathrm{~nm}$, determined from the mean of all ear and stover scans observed, respectively. For water, we would expect an absorption peak at $970 \mathrm{~nm}$ from a vibrational overtone of the $\mathrm{O}-\mathrm{H}$ bond.

The calibration set consisted of 737 samples out of the 739 samples taken and over a wide range of ear and stover moisture contents, no outliers were removed based on spectra, but two samples were omitted due to missing reference data (table 1). The data represented a wide range of moisture contents from $27 \%$ to $55 \%$ w.b. and $49 \%$ to $76 \%$ w.b., for

Table 1. Statistics of calibration results for ear and stalk moisture contents using SCIO device 1.

\begin{tabular}{ccc}
\hline Anatomical Fraction & \multicolumn{2}{c}{ Ear } \\
Parameter & \multicolumn{3}{c}{ Moisture Content (\% w.b.) } \\
\cline { 2 - 3 } SEL & \multicolumn{3}{c}{0.348} \\
N & 0 & 737 \\
Outliers removed & 27 & 0 \\
Min & 55 & 49 \\
Mean & 81 & 76 \\
Max & 11 & 83 \\
SD & 3.1 & 6.3 \\
SEC & 0.93 & 4.4 \\
R C & 3.1 & 0.51 \\
SECV & 0.92 & 4.4 \\
R CV & 1.2 & 0.47 \\
NIR repeatability & 4 & 1.4 \\
Number of terms & 3.7 & 11 \\
RPD_C & 3.6 & 1.4 \\
RPD_CV & 10 & 10 \\
Cross-validation segments & \multicolumn{3}{c}{ 740-1050/1 } \\
Wavelength range/step (nm) & \multicolumn{3}{c}{ D-1,1,15 } \\
Pretreatments & \multicolumn{3}{c}{ PLS } \\
Regression method &
\end{tabular}

*D - Savitzky-Golay derivative - smoothing kernel of length 15, quadratic interpolation, first derivative

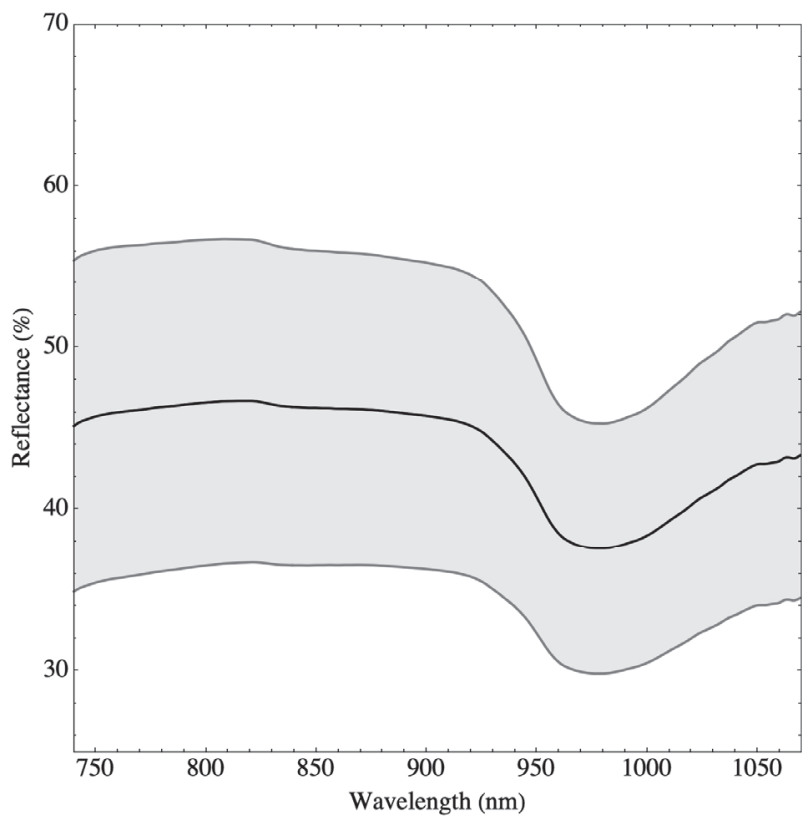

ears and stalks, respectively. Comparing the high standard deviation of the moisture contents to the low standard error of the laboratory (SEL) for the oven reference method, there should be a good opportunity for NIRS calibration.

The model optimization process involved increasing and decreasing the number of latent variables and spectral math transformations for both ear and stover models. The best model performance for both models was obtained with a Savitzky-Golay filter smoothing kernel of length 15 , quadratic interpolation, first derivative. Ultimately the stover model was abandoned due to poor model performance. One observation that could explain this result is the moisture data for stover had a lower range and standard deviation compared to the ear data.

A small numerical difference was observed between the standard error of calibration (SEC) and the standard error of cross-validation (SECV), indicating that the number of samples was sufficient for developing a calibration (Dardenne, 2009). Ear and stover scans were considered as separate calibrations. While the coefficient of determination and RPD show good agreement between predicted and actual ear moisture, a similar model was not attainable for the stover moisture content with this instrument.

Next, we considered model performance on an independent validation set (table 2). However, the validation results indicate that our model is not robust enough for prediction, as indicated by a low coefficient of determination. When utilizing the same instrument between calibration and validation there was a marked reduction in performance in terms of $\mathrm{R}^{2}$ and RMSEP.

During the validation scans, we added a second $\mathrm{SCiO}$ device (table 2, fig. 7). The two devices' differences were primarily observed as bias indicated by the large difference between the RMSEP and SEP. This bias could be corrected by including additional $\mathrm{SCiO}$ devices in the calibration data or by exploring calibration transfer techniques between the instruments. 
Table 2. Statistics of validation results for prediction of ear moisture using the same device as the calibration set (device 1) and an independent instrument (device 2).

\begin{tabular}{ccc}
\hline Anatomical Fraction & \multicolumn{2}{c}{ Ear } \\
SCIO Device & 1 & 2 \\
Parameter & Moisture content (\% w.b.) \\
\cline { 2 - 3 } N & \multicolumn{2}{c}{99} \\
Outliers removed & 0 \\
Min & 37 & 37 \\
Mean & 46 & 46 \\
Max & 55 & 55 \\
SD & 3.7 & 3.7 \\
R ${ }^{2}$ & 0.52 & 0.52 \\
RMSEP & 4.0 & 9.3 \\
SEP & 3.9 & 3.6 \\
RSD & 3.9 & 3.6 \\
NIR repeatability & 1.3 & 1.0 \\
Bias & -0.95 & 8.6 \\
Intercept & -6.4 & 3.3 \\
Slope & 1.5 & 1.5 \\
\hline
\end{tabular}

\section{CONCLUSIONS}

Estimation of whole plant moisture is critical for optimum harvest timing for corn silage. The two major aboveground biomass components, ear, and stover differ significantly in moisture content before harvest, with minimal change in stover moisture until the harvest season is past. Based on the work presented here, we offer the following conclusions.

- Quadratic relationships were established to relate ear moisture or stover moisture to whole-plant moisture,

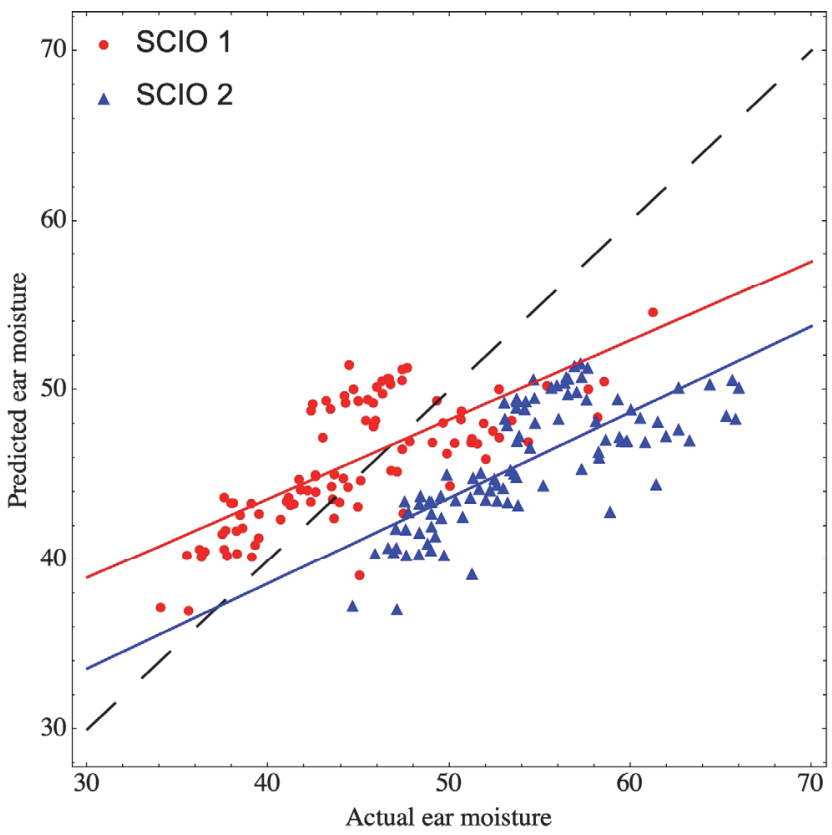

Figure 7. Relationship between actual ear moisture (determined by oven $\mathrm{DM}$ procedure) and predicted from two $\mathrm{SCiO}$ devices. The $\mathrm{SCiO} 1$ device was utilized to generate all calibration data. Each dot (device 1) or triangle (device 2) represents an ear moisture prediction of a spectra averaged from five scans compared to actual. The solid red line represents a 1:1 relationship between predicted and actual moisture contents; the dashed black line indicates a linear relationship between predicted and actual moisture for device one, and the gray line represents device two. and they explained $90 \%$ and $84 \%$ of whole plant moisture, respectively.

- Based on our observations, the moisture content of a corn field can be estimated within $+1 \%$ w.b. in 19 out of 20 fields by sampling 5 to 10 plants.

- The calibration offered by $\mathrm{SCiO}$ was successful at predicting oven-dried moisture content based on traditional NIRS metrics of $\mathrm{R}^{2}=0.92$, $\mathrm{RMSE}=3.6$, and $\mathrm{RPD}=3.2$. However, the $95 \%$ prediction bands were $\pm 6.9 \%$ w.b., which would indicate little utility in estimating ear moisture content.

- Based on a prediction model that was developed using the data collected for this study, a significant instrument-to-instrument bias was observed, indicating the necessity of including multiple $\mathrm{SCiO}$ devices in calibration spectra collection or the use of a calibration transfer model.

\section{ACKNOWLEDGMENTS}

Funding for this study was provided by the New York Farm Viability Institute, State of New York. The authors thank Robert Deubler for assistance in sample collection and processing.

\section{DECLARATION OF INTEREST}

The authors declared no potential conflicts of interest with respect to the research, authorship and/or publication of this article.

\section{REFERENCES}

Arriola, K. G., Kim, S. C., Huisden, C. M., \& Adesogan, A. T. (2012). Stay-green ranking and maturity of corn hybrids: 1 . Effects on dry matter yield, nutritional value, fermentation characteristics, and aerobic stability of silage hybrids in Florida. J. Dairy Sci., 95(2), 964-974. https://doi.org/10.3168/jds.20114524

Bec, K. B., Grabska, J., Siesler, H. W., \& Huck, C. W. (2020). Handheld near-infrared spectrometers: Where are we heading? NIR news, 31(3-4), 28-35. https://doi.org/10.1177/0960336020916815

Cherney, D. J. R., Digman, M., \& Cherney, J. H. (2021). Day-today variation in forage and mixed diets in commercial dairy farms in New York. Appl. Animal Sci., 37(1), 11-20. https://doi.org/10.15232/aas.2020-02105

Cherney, J. H., Cherney, D. J. R., \& Casler, M. D. (1996). Sampling forage corn for quality. Can. J. Plant. Sci., 76(1), 93-99. https://doi.org/10.4141/cjps96-014

Cox, W. J., \& Cherney, J. H. (2005). Timing corn forage harvest for bunker silos. Agron. J., 97(1), 142-146.

Crocombe, R. A. (2018). Portable spectroscopy. Appl. Spec., 72, 1701-1751. https://doi.org/10.1177/0003702818809719

Darby, H. M., \& Lauer, J. G. (2002). Harvest date and hybrid influence on corn forage yield, quality, and preservation. Agron. J., 94(3), 559-566. https://doi.org/10.2134/agronj2002.5590

Dardenne, P. (2010). Some considerations about NIR spectroscopy: Closing speech at NIR-2009. NIR news, 21, 8-14. https://doi.org/10.1255/nirn.1165

Digman, M. F., \& Shinners, K. J. (2008). Real-time moisture measurement on a forage harvester using near-infrared reflectance spectroscopy. Trans. ASABE, 51(5), 1801-1810. https://doi.org/10.13031/2013.25295 
Donnelly, D. M., Dorea, J. R., Yang, H., \& Combs, D. K. (2018). Technical note: Comparison of dry matter measurements from handheld near-infrared units with oven drying at $60^{\circ} \mathrm{C}$ for 48 hours and other on-farm methods. J. Dairy Sci., 101, 9971-9977. https://doi.org/10.3168/jds.2017-14027

Ettle, T., \& Schwarz, F. J. (2003). Effect of maize variety harvested at different maturity stages on feeding value and performance of dairy cows. Animal Res., 52(4), 337-349. https://doi.org/10.1051/animres:2003023

Foster, A. J., Kakani, V. G., Ge, J., \& Mosali, J. (2013). Rapid assessment of bioenergy feedstock quality by near infrared reflectance spectroscopy. Agron. J., 105(6), 1487-1497. https://doi.org/10.2134/agronj2013.0100

Funk, D. B. (2001). An investigation of the nature of the radiofrequency dielectric response in cereal grains and oilseeds with engineering implications for moisture meters. PhD diss. Kansas City: University of Missouri.

Funk, D., \& Gillay, Z. (2020). Unified grain moisture algorithm recipe book. Washington, DC: USDA - Agricultural Marketing Service and Federal Grain Inspection Service. Retrieved from https://www.ams.usda.gov/sites/default/files/media/UGMAReci peBook.pdf

Goldring, D., Sharon, D., Brodetzki, G., Ruf, A., Kaplan, M., Rosen, S.,... Nir, I. (n.d.). Spectrometrysystem with diffuser having output profile independent of angle of incidence and filters. U.S. Patent 9,448,114.
Lewis, A. L., Cox, W. J., \& Cherney, J. H. (2004). Hybrid, maturity, and cutting height interactions on corn forage yield and quality. Agron. J., 96(1), 267-274.

Long, E. A., Ketterings, Q. M., Russell, D., Vermeylen, F., \& DeGloria, S. (2016). Assessment of yield monitoring equipment for dry matter and yield of corn silage and alfalfa/grass. Precis. Agric., 17(5), 546-563. https://doi.org/10.1007/s11119-0169436-y

Malley, D. F., McClure, C., Martin, P. D., Buckley, K., \& McCaughey, W. P. (2005). Compositional analysis of cattle manure during composting using a field-portable near-infrared spectrometer. Commun. Soil Sci. Plant Analysis, 36(4-6), 455475. https://doi.org/10.1081/CSS-200043187

SCiO. (2021). Ear Corn Analysis in Seconds. Consumer Physics, Tel-Aviv, Israel. Retrieved from https://www.consumerphysics.com/ear-corn-analysis/

Thomas, H., \& Smart, C. M. (1993). Crops that stay green. Ann. Appl. Biol., 123(1), 193-219. https://doi.org/10.1111/j.17447348.1993.tb04086.x

Ward, A., Nielsen, A. L., \& Moller, H. (2011). Rapid assessment of mineral concentration in meadow grasses by near infrared reflectance spectroscopy. Sensors, 11(5), 4830-4839. https://doi.org/10.3390/s110504830

Yan, H., \& Siesler, H. W. (2018). Hand-held near-infrared spectrometers: State-of-the-art instrumentation and practical applications. NIR news, 29(7), 8-12. https://doi.org/10.1177/0960336018796391 